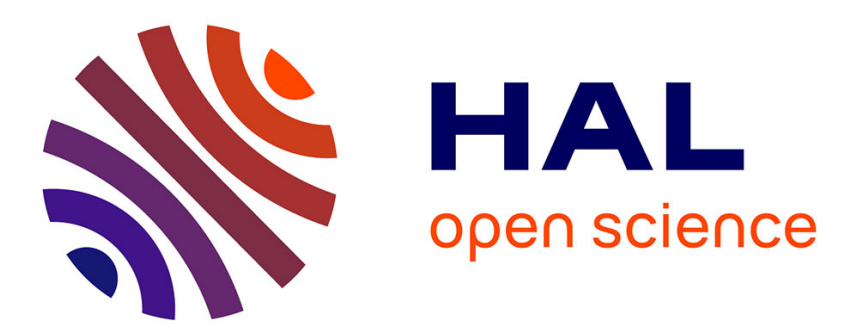

\title{
Investigation of Thermal Processes in High Power Laser Bars by Thermoreflectance Spectroscopy
}

\author{
K. Piersciñski, D. Pierscinska, A. Kozlowska, M. Bugajski
}

\section{To cite this version:}

K. Piersciñski,, D. Pierscinska, A. Kozlowska, M. Bugajski. Investigation of Thermal Processes in High Power Laser Bars by Thermoreflectance Spectroscopy. THERMINIC 2007, Sep 2007, Budapest, Hungary. pp.168-173. hal-00202555

\section{HAL Id: hal-00202555 https://hal.science/hal-00202555}

Submitted on 7 Jan 2008

HAL is a multi-disciplinary open access archive for the deposit and dissemination of scientific research documents, whether they are published or not. The documents may come from teaching and research institutions in France or abroad, or from public or private research centers.
L'archive ouverte pluridisciplinaire $\mathbf{H A L}$, est destinée au dépôt et à la diffusion de documents scientifiques de niveau recherche, publiés ou non, émanant des établissements d'enseignement et de recherche français ou étrangers, des laboratoires publics ou privés. 


\title{
Investigation of thermal processes in high power laser bars by thermoreflectance spectroscopy
}

\author{
K. Pierściński, D. Pierścińska, A. Kozłowska and M. Bugajski \\ Institute of Electron Technology, Al. Lotników 32/46, 02668 Warszawa, Poland
}

\begin{abstract}
In this paper we present results of the analysis of the thermoreflectance (TR) measurements performed on the high power laser diodes and laser bar emitting at $808 \mathrm{~nm}$. Thermoreflectance is a modulation technique relying on periodic facet temperature modulation induced by pulsed current supply of the laser. The periodic temperature change of the laser induces variation of the refractive index and consequently modulates probe beam reflectivity. Spatially resolved thermoreflectance spectroscopy is applied to measure line-scans and maps of temperature distribution at the laser mirrors and emitter facets in laser bar. However, to get the absolute values of temperatures, thermoreflectance needs calibration. Different calibration methods, such us: $\mu$ Raman spectroscopy and in situ determination of thermoreflectance coefficient $\left(\mathrm{C}_{\mathrm{TR}}\right)$ will be discussed. The knowledge of temperature distribution at laser facets gives insight into thermal processes occurring at devices' facets and consequently leads to the increased reliability and substantially longer lifetimes of such structures.
\end{abstract}

\section{INTRODUCTION}

A growing demand for high power optical sources (singleemitters and laser bars) leads to the race towards improving device reliability and increasing output power. The extracted optical power out of one laser bar has increased continuously during the last decades, from about $1.6 \mathrm{~W}$ [1] 23 years ago to more than $900 \mathrm{~W}$ [2] at present. Many different aspects of device design had to be optimized in order to reach such extreme output powers. The biggest threat to the devices pose strongly localized facet heating (optical power densities reaching $\sim 27 \mathrm{MW} / \mathrm{cm}^{2}$ ) [3] and catastrophic optical mirror damage (COMD) [4]. These effects cause laser and laser bar degradation and consequently limit the emitted optical power and device lifetime. The knowledge about heat distribution in the device, and identification of sources of excessive heating is very important to achieve reliable operation at high brightness. In this paper spatially resolved thermoreflectance spectroscopy $[5,6]$ is applied to measure line-scans and maps of temperature distribution at the laser mirrors and emitter facets in laser bar. Presented results show the strength of this technique in studying thermal management problems in high power semiconductor lasers.

\section{THERMOREFLECTANCE TECHNIQUE}

\section{A. Theory}

Facet temperature measurements are performed using thermoreflectance (TR) spectroscopy. This technique was used for the first time for measuring facet temperature of laser diodes by E. W. Epperlein in 1991 [7]. Like other optical modulation spectroscopic techniques, the method relies on the measurement of the response of the optical constants of the material to the applied periodic perturbation. In the thermoreflectance spectroscopy, reflectance spectrum is modulated by periodic variation of the temperature of the sample. The modulation of temperature results in a change of dielectric function $\varepsilon(\omega)$ of the crystal which is induced by a shift of the band gap energy Eg and by the change of the broadening parameter $\Gamma[8,9]$ :

$$
\Delta \varepsilon=\frac{\partial \varepsilon}{\partial T} \Delta T=\frac{\partial \varepsilon}{\partial E_{g}} \frac{d E_{g}}{d T} \Delta T+\frac{\partial \varepsilon}{\partial \Gamma} \frac{d \Gamma}{d T} \Delta T
$$

The periodic variation of the temperature of the sample can by produced by heater or by applying a periodically chopped laser beam to the sample. The variation in the sample reflectance $(\Delta \mathrm{R})$ is related to the temperature variation $(\Delta \mathrm{T})$ through the following equation:

$$
\frac{\Delta R}{R}=\frac{1}{R} \frac{\partial R}{\partial T} \Delta T
$$

The relative variation of the sample reflectance $\Delta R / R$ is linear versus the temperature variation $\Delta \mathrm{T}$ and consequently the measurement of the sample reflectance allows for determination of local temperature increase according to the following formula: 
$\Delta T=\left(\frac{1}{R} \frac{\partial R}{\partial T}\right)^{-1} \frac{\Delta R}{R}=C_{T R} \frac{\Delta R}{R}$

Here $C_{\mathrm{TR}}$ is the thermoreflectance coefficient, which varies strongly with material [10] and the wavelength of the probe beam [11], and its typical magnitude ranges from $10^{-6}$ to $10^{-4}$ for metals and semiconductors. Therefore, it should be determined experimentally for each investigated device. In this work the TR coefficient has been determined experimentally by $\mu$-Raman spectroscopy [6] and by in situ calibration procedures performed in the TR set-up. Other method which provides temperature calibration is microphotoluminescence ( $\mu \mathrm{PL})$. This method was employed in our previous TR measurements $[5,12]$.

\section{B. Calibration procedures}

In the following section the optimisation of experimental technique and calibration procedures will be presented. The first procedure (the selection of the optimum probe beam wavelength) performed for the laser bar will be described. It relies on measurement of differential change of the reflectance with temperature as a function of wavelength $(1 / \mathrm{R}) \mathrm{dR} / \mathrm{dT}(\lambda)$. Here the data were collected in the range of $440 \mathrm{~nm}$ to $850 \mathrm{~nm}$. The appropriate choice of the probe beam wavelength maximizes thermoreflectance signal and strongly enhances sensitivity of the technique to small temperature changes. This optimization needs to be performed for each examined structure before the actual thermoreflectance measurements. This method of TR signal optimization can also be used as in situ method to estimate the thermoreflectance coefficient $\mathrm{C}_{\mathrm{TR}}$ [13]. In this case the reflectance spectra for various temperatures $\mathrm{T}$ were acquired and $(1 / \mathrm{R}) \mathrm{dR} / \mathrm{dT}(\lambda)$ has been calculated numerically. To guarantee stable conditions the temperature of the sample had to be stabilized and measured precisely.

This above described method was employed to measure thermoreflectance sensitivity spectrum for the GaAs/AlGaAs high power laser bar structure (Fig.1). A maximum TR signal was obtained for shortest wavelengths available, i.e., in the range $440 \mathrm{~nm}$ to $470 \mathrm{~nm}$. In the remaining spectral region, the TR signal is substantially lower. For practical reasons $456 \mathrm{~nm}$ $(2.81 \mathrm{eV})$ line of an $\mathrm{Ar}^{+}$laser was used in measurement of this device. At the $456 \mathrm{~nm}$ probe beam wavelength the thermoreflectance coefficient equals $\mathrm{C}_{\mathrm{TR}}=2.9 \times 10^{4}$. This value of $\mathrm{C}_{\mathrm{TR}}$ is the average TR coefficient for GaAs substrate and for active region (mainly AlGaAs), because both substrate and active region were illuminated. The active region is less then $7 \%$ of mirror surface, therefore we assume this value of $\mathrm{C}_{\mathrm{TR}}$ as a good estimation of thermoreflectance coefficient for $\mathrm{GaAs}$ substrate. In order to obtain the value of $\mathrm{C}_{\mathrm{TR}}$ for active device layers (epitaxial layers) other, more spatially selective, calibration methods need to be employed.

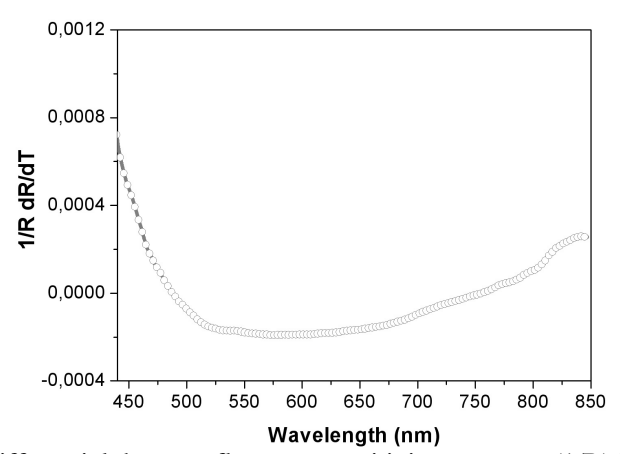

Fig. 1 Differential thermoreflectance sensitivity spectrum $(1 / \mathrm{R}) \mathrm{dR} / \mathrm{dT}(\lambda)$ measured on GaAs/AlGaAs high power laser bar mirror

The calibration procedure which was used in this case, relies on measuring reflectance line-scans starting at the substrate and going towards the edge of the p-type contact for different values of temperature from 20 to $60{ }^{\circ} \mathrm{C}$. The reflectance was measured for selected probe beam wavelength of $456 \mathrm{~nm}$. The temperature of the sample was controlled by Peltier element and temperature controller. The reflectance spectra for various temperatures $\mathrm{T}$ were acquired and $(1 / \mathrm{R}) \mathrm{dR} / \mathrm{dT}$ has been calculated numerically for the selected wavelength of probe beam $(456 \mathrm{~nm})$. The thermoreflectance coefficient obtained by this procedure was $\mathrm{C}_{\mathrm{TR}(\mathrm{AR})}=5.8 \times 10^{4}$

The obtained results were cross-checked by $\mu$-Raman spectroscopy technique which provides absolute temperature measurements. This is beyond any doubts an advantage of Raman technique but at the same time the fact that this is an ex situ measurement excludes it from routine laboratory practice. For $\mu$-Raman spectroscopy a Dilor spectrometer equipped with a microscope and a liquid- $\mathrm{N}_{2}$-cooled charge coupled device (CCD camera) was used. The measurements allowed for synchronous monitoring of the Stokes and antiStokes GaAs- and AlAs-like TO-phonon peaks. The 514.5 $\mathrm{nm}$ line of an $\mathrm{Ar}^{+}$laser served as excitation (excitation power $\sim 850 \mathrm{~mW}$, spot diameter $\varnothing_{1 / e} \sim 1 \mu \mathrm{m}$ ). Since the $\mu$-Raman technique is spatially selective, the temperature calibration is done straightforwardly by the measurement of spectra at the relevant locations at the facet (substrate, epitaxial layer) for a nonoperating device in the temperature range between 20 and $100^{\circ} \mathrm{C}$. The heat sink, which is stabilized for the standard measurement at $(25 \pm 0.1)^{\circ} \mathrm{C}$, allows for active alignment of the device waveguide with respect to the microscope objective by using $x-y-z$ piezo-translation stages. Details on the setup are given in $[3,12]$. Temperature data are extracted from line-position shifts (device on/off) and are crosschecked by Stokes-anti-Stokes ratio analysis.

\section{Thermoreflectance experimental set-up}

The focused beam TR experimental set-up used in the experiments is shown in Fig. 2. 


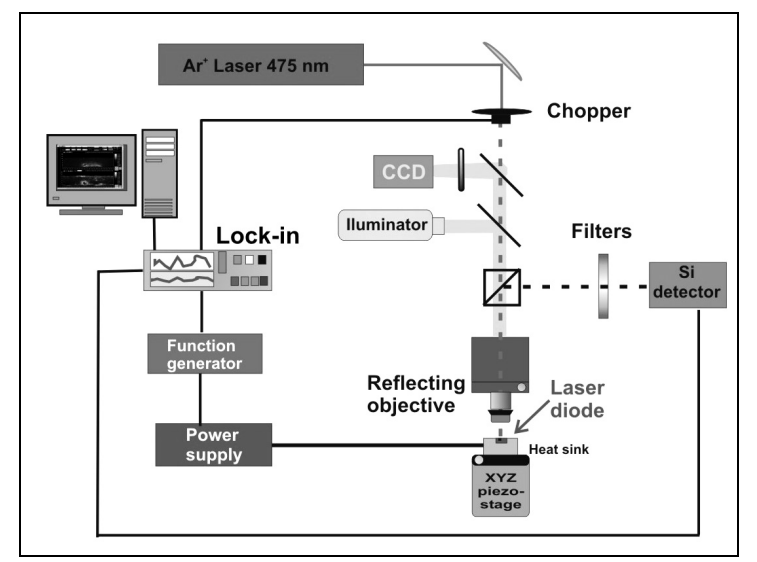

Fig. 2 Experimental set-up for thermoreflectance mapping of laser and laser bar mirrors

Different sources of probe beam can be used, e.g.: $\mathrm{Ar}^{+}$laser lines, He-Ne laser line, $\mathrm{HeCd}$ laser line. The appropriate wavelength (for examined structure) was determined by described earlier probe beam wavelength optimization procedure. The probe beam was focused with the reflecting microscope objective to the spot of diameter $\varnothing_{1 / \mathrm{e}} \sim 0.6 \mu \mathrm{m}$. The additional chopping frequency allows for simultaneous measurement of reflectivity of the sample. It enables to obtain in the same experiment the value of the reflectivity change $\Delta \mathrm{R}$ and the reflectivity $\mathrm{R}$ in each point of examined area. By dividing $\Delta \mathrm{R}$ by $\mathrm{R}$ we can eliminate features originating from mechanical roughness of the surface and other artefacts which scatter probe beam but have nothing to do with actual temperature change. Another method that provides the experimental value of normalized reflectivity $(\Delta R / R)$ is to divide the ac output signal from the $\mathrm{Si}$ photodetector by its dc component. The main part of the experimental set-up is based on a microscope, which provides proper mechanical stability and optimal beam alignment (see Fig. 3).

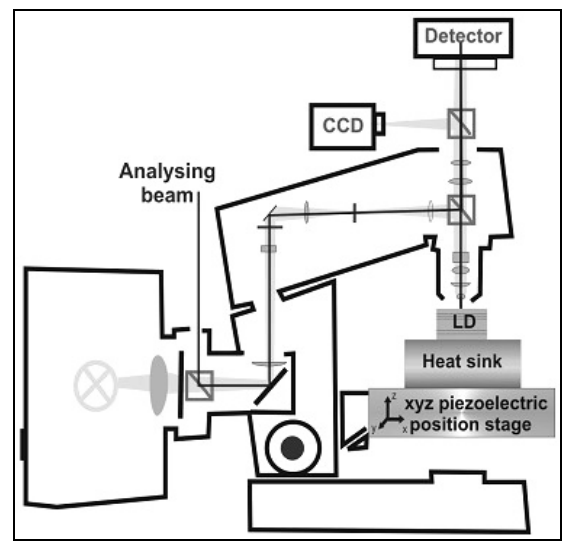

Fig. 3 Scheme of the main part of thermoreflectance set-up based on a commercial microscope

The devices are mounted on the heatsink. The base temperature is stabilized by means of water cooled Peltier element and the temperature controller. The heatsink is mounted on a high precision $\mathrm{x}-\mathrm{y}-\mathrm{z}$ piezo-translator stage to align laser mirror with respect to the laser probe beam. Using piezoelectrically driven translator stages allows mapping of laser facet temperature with sub-micron resolution. The piezo-translation stages provide $300 \mu \mathrm{m}$ travel distance in $\mathrm{x}-\mathrm{y}$ plane with minimum step of $0.1 \mu \mathrm{m}$. The device is operated in quasi-cw (quasi-continuous wave) mode and is subjected to the thermal effects associated with $\mathrm{CW}$ operation.

\section{Examined Samples}

\section{Diode Laser Structures}

The devices studied in this work were the broad-area doublebarrier separate confinement heterostructure (DB SCH SQW) lasers. They are designed for $808 \mathrm{~nm}$ emission and were grown by low-pressure metal organic chemical vapor phase epitaxy - MOVPE. The active region of the device consists of $15 \mathrm{~nm}$ thick GaAsP quantum well surrounded by $98 \mathrm{~nm}$ thick $\mathrm{Al}_{0.3} \mathrm{Ga}_{0.7} \mathrm{As}$ waveguide layers. The facets are HR/LR coated by AlN-Si/AlN multilayers. The devices were mounted episide down onto copper blocks [14].

\section{Laser Bar Structures}

The investigated device was high power $10 \mathrm{~mm}$ laser bar consisting of 25 emitters with $300 \mu \mathrm{m}$ wide stripes. The individual emitters are separated by $85 \mu \mathrm{m}$ wide optically and electrically isolated area. The device was mounted "epi-side down" onto a $\mathrm{Cu}$ heat sink. The threshold current for $\mathrm{CW}$ operation at $25{ }^{0} \mathrm{C}$ was equal to $12 \mathrm{~A}$; the slope efficiency was $1.25 \mathrm{~W} / \mathrm{A}$, the maximum output power was $60 \mathrm{~W}$. Figure 4 presents scheme of the laser bar structure.

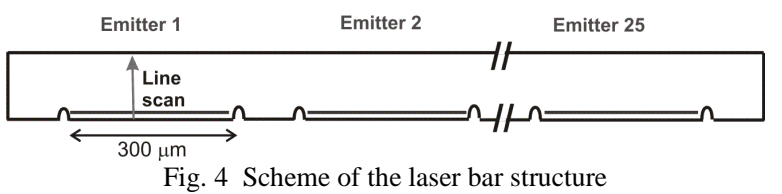

\section{RESULTS}

\section{Diode Laser Structures}

The laser diodes were operated in quasi-CW mode with square current pulses of amplitude varying from $800 \mathrm{~mA}$ to $2000 \mathrm{~mA}$. The filling factor was $50 \%$ and the frequency 300 $\mathrm{Hz}$. The temperature of the heat sink was stabilized at $25^{\circ} \mathrm{C}$. The curves shown in Fig. 5 were obtained as vertical scans starting at the substrate and going towards the edge of the ptype contact. The lines represent TR signals for different values of driving current. At the interface between heterostructure and substrate a discontinuity- step in the intensity of TR signal is observed for all values of applied current. This intensity change is solely related to the different 
reflectance properties of the materials composing the laser structure and it does not reflect the true temperature profile.

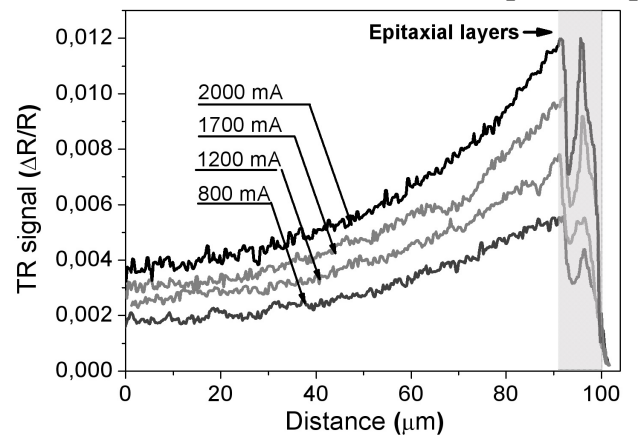

Fig. 5 Vertical TR scans (perpendicular to the junction) for different drive current levels from $800 \mathrm{~mA}$ to $2000 \mathrm{~mA}$

In order to recalculate the thermoreflectance signal to temperature, TR coefficients $\mathrm{C}_{\mathrm{TR}}$ need to be determined for each material in the examined area. For that purpose we have used $\mu$-Raman spectroscopy which provided the following values of $\mathrm{C}_{\mathrm{TR}}$ coefficient $-\mathrm{C}_{\mathrm{TR}(\mathrm{GaAs})}=1.62 \times 10^{4}$ for $\mathrm{GaAs}$ substrate and $\mathrm{C}_{\mathrm{TR}(\mathrm{AR})}=3.41 \times 10^{4}$ for $\mathrm{AlGaAs}$ waveguide and cladding regions.

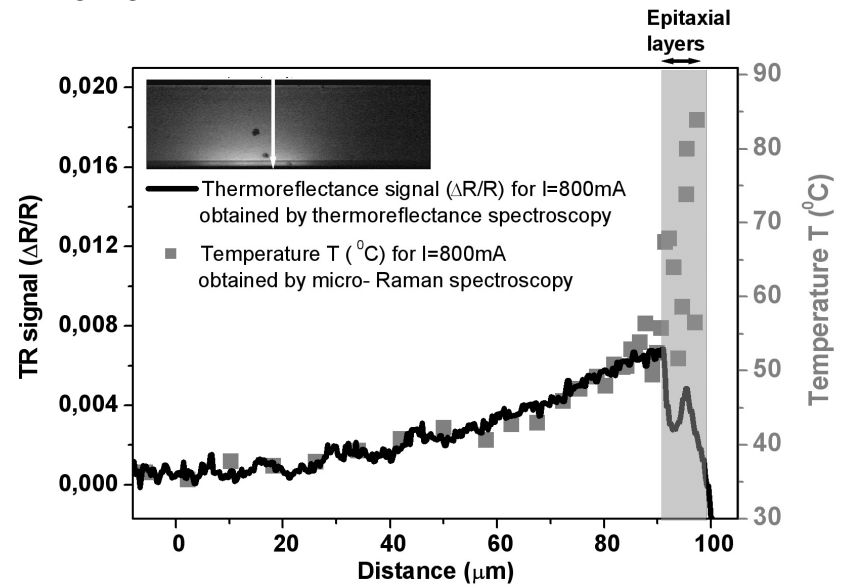

Fig. 6 Temperature distribution across the laser front facet as determined by $\mu$ - Raman spectroscopy at $800 \mathrm{~mA}$ driving current (grey squares) and thermoreflectance signal distribution at the same current (black line)

Figure 6 presents values of temperature obtained from $\mu$ Raman measurements and TR vertical scans, before recalculating into real temperature. It is very important to stress that in $\mu$-Raman experiment absolute value of temperature on the laser facet is obtained, whereas in TR spectroscopy the reflectivity change proportional to the temperature change is measured. After performing the appropriate calibration of TR signal, based on the results of $\mu$-Raman measurements the temperature distribution across the laser facet was obtained (Fig. 7).

Details of the calibration procedure are given in ref. [6]. Figure 7 shows vertical scans recalculated to temperature for all values of supply current. The temperature increase is the highest in the active and waveguide region $(\Delta \mathrm{T}=110 \mathrm{~K}$ for $\mathrm{I}=2 \mathrm{~A}$ ). It can be seen that for all values of current, the temperature decreases rapidly at the distance of about 3-5 $\mu \mathrm{m}$ from the active region. The overall shape of the temperature distribution indicates a diffusive heat transfer mechanism in the substrate, going to the of the device.

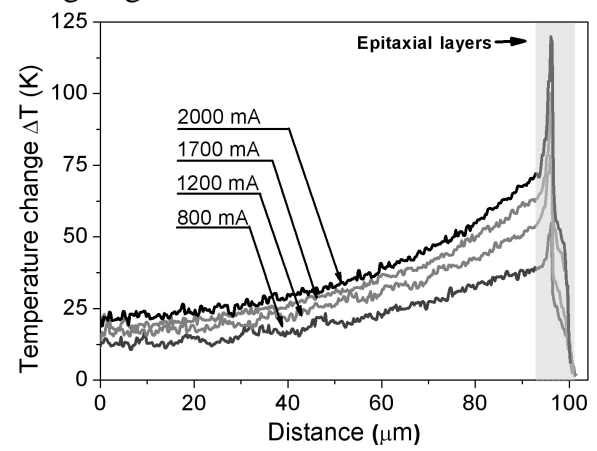

Fig. 7 Facet temperature distribution in the direction perpendicular to junction for different driving currents.

\section{Laser Bar Structures}

The $10 \mathrm{~mm}$ laser bar were operated in quasi-CW mode with square current pulses of amplitude up to $40 \mathrm{~A}$. The filling factor was $50 \%$ and the frequency $300 \mathrm{~Hz}$. The temperature of the heat sink was stabilized at $25{ }^{\circ} \mathrm{C}$. The line-scans starting at the active region towards substrate were measured in the center of each emitter.

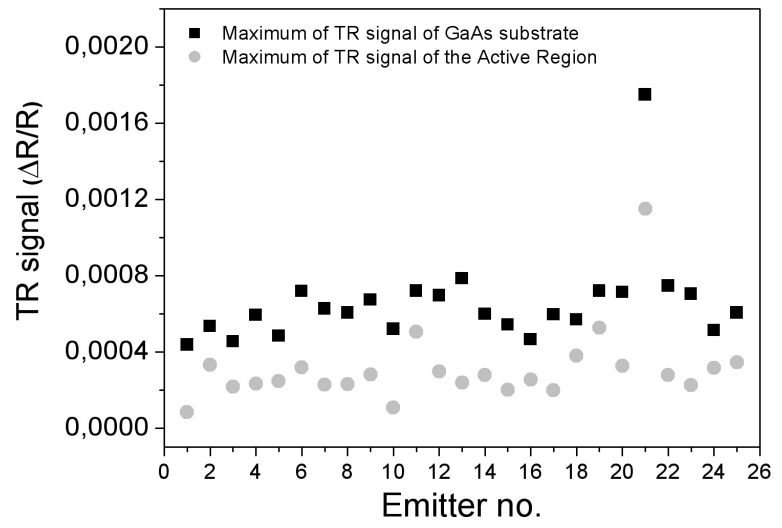

Fig. 8 Comparison of the maximum of TR signal from GaAs substrate and from the active region for each of the laser bar emitters

Figure 8 shows that the maximum of TR signal obtained for GaAs lies very close to epitaxial layers whereas the maximum of TR signal from epi-layers is observed at the center of active region for each emitter. The values of TR signal for each emitter were similar, except for the emitter no. 21. The reason for this behavior will be discussed in detail further in the text.

Figure 9 shows TR signal line-scans for selected emitters (no.21 and no.4), showing characteristic behavior (step in the intensity of TR signal at the interface between epi-layers and the substrate). 


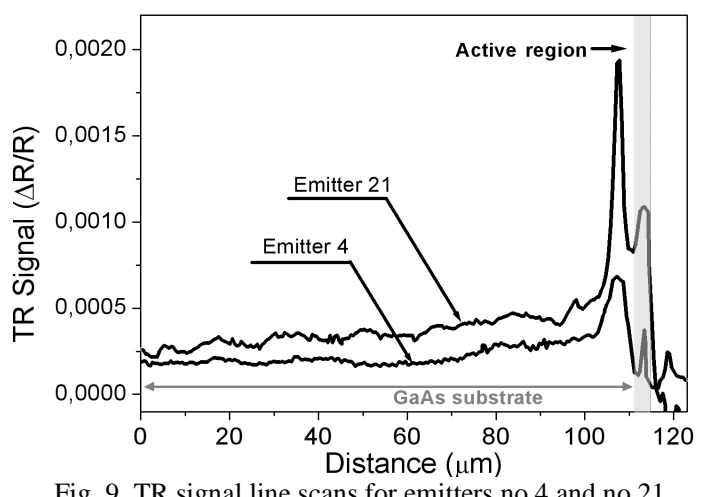

Fig. 9 TR signal line scans for emitters no. 4 and no. 21

Qualitatively the observed behavior is the same as for single emitters and it can be solely attributed to the difference in thermoreflectance coefficient for the substrate and epi-layers. The subsequent studies were devoted towards explanation of different temperature behavior of emitter no.21. The TR map for this emitter, shown in Fig.10, evidences pronounced degradation of the facet and a large hot spot at $\mathrm{x}=200 \mu \mathrm{m}$. The presence of the hot spot at the facet of the emitter indicates the ongoing mirror degradation process, which eventually leads to COMD failure. From the previous studies of similar cases [Therminic 2006] it is known that emitter failure creates thermal run-way able to kill with time the whole device. Although the increase of the mirror temperature at the hot spot $(\Delta \mathrm{T}=120)$ is well below the mirror melting point it already posses a serious danger to the device because of the positive feedback mechanism governing the COMD process.

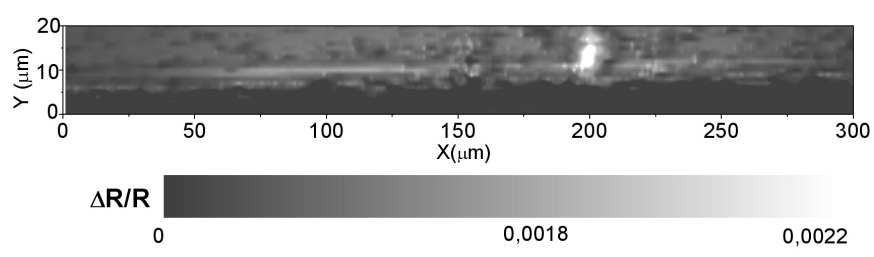

Fig. 10 TR map $(300 \mu \mathrm{m} \times 30 \mu \mathrm{m})$ for emitter no. 21 at supply current $40 \mathrm{~A}$

The thermoreflectance (TR) results were recalculated to temperature, using suitable thermoreflectance coefficients estimated for different areas of the laser bar. In case of GaAs substrate the thermoreflectance coefficient was $\mathrm{C}_{\mathrm{TR}(\mathrm{GaAs})}=2.9$ $\mathrm{x} 10^{4}$ and for active region $-\mathrm{C}_{\mathrm{TR}(\mathrm{AR})}=5.8 \times 10^{4}$. It is worth noting that these values differ from values of $\mathrm{C}_{\mathrm{TR}}$ obtained for single laser diode, where the appropriate coefficients were $\mathrm{C}_{\mathrm{TR}(\mathrm{GaAs})}=1.62 \times 10^{4}$ and $\mathrm{C}_{\mathrm{TR}(\mathrm{GaAs})}=3.41 \times 10^{4}$. This confirms the influence of the overlayer (dielectric coatings) on the reflectance measurements. Figure 11 presents the temperature line-scans for emitters no. 4 and no. 21 obtained from TR signal after recalculation.

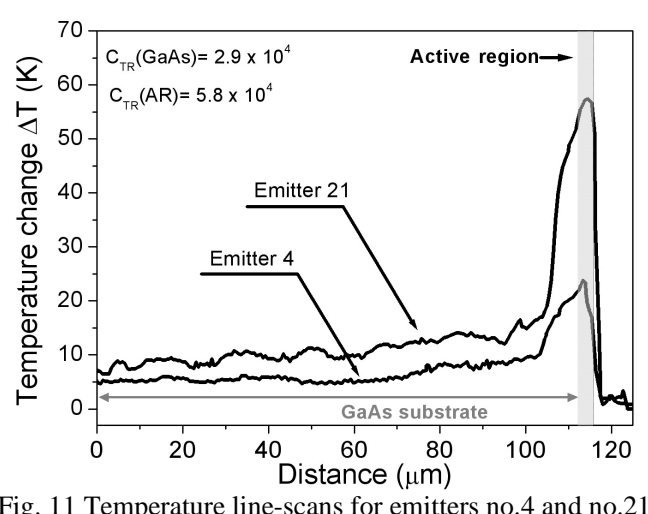

Fig. 11 Temperature line-scans for emitters no. 4 and no. 21 The complete temperature map of the emitter no. 21, recalculated from TR data, is shown in Fig. 12.

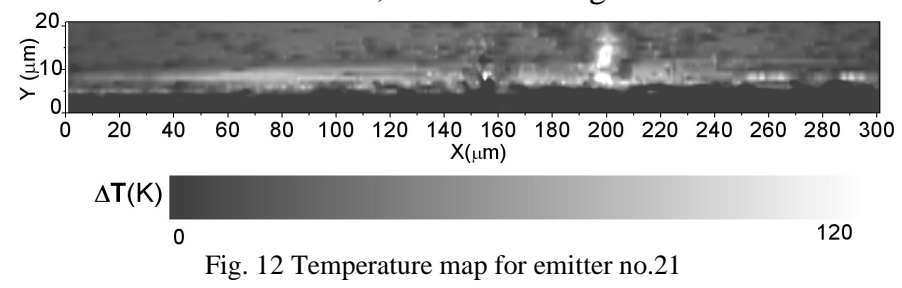

Mapping of the active region is very important in localising the overheating regions of the mirror which are exposed to COMD. This area would have been missed while measuring only line-scans in the center of the emitter.

\section{CONCLUSIONS}

In this paper the thermoreflectance measurements of high power laser diodes and laser bars have been presented. We stress the importance of calibration of the thermoreflectance for obtaining reliable thermal data. The results confirm strong dependence of $\mathrm{C}_{\mathrm{TR}}$ coefficient on the probe wavelength and material of analysed structures. In order to obtain full information about the state of the facets the temperature distribution has to be mapped at least over the of whole active region, as the hot spots can easily be missed when recording only line-scans. It has been found that the presence of the hot spots at the mirror facets is an indicative of the ongoing degradation process. This is equally true for single emitters as well as for laser bars, although in the later case this can have serious consequences not only to particular emitter but to the device as a whole since the failure of the emitter creates thermal run-way able to kill with time the whole device.

\section{ACKNOWLEDGMENTS}

The authors would like to thank Dr. Jens W. Tomm from Max Born Institute, Berlin, for providing the laser bars for the measurements and Dr. Andrzej Malag from Institute of Electronic Materials Technology, Warsaw, for providing of the laser diodes. This work was partly supported by the Polish Ministry of Science and Higher Education under grants: 3T11B00829 and N515 013 32/0847. 


\section{REFERENCES}

F. Kappeler et al., $9^{\text {th }}$ IEEE Int. Semicont. Laser Conf., 90,

(1984)

[2] Hanxuan Li, et al, Proc. SPIE, 6456, 64560C, Feb. 7, (2007)

[3] J. W. Tomm,et al, App.Phys. A, 70, 377 (2000)

[4] R. Puchert, J.W. Tomm, A. Jaeger, A. Bärwolff, J.Luft, W.Spath, Appl. Phys. A, 66, 483 (1998)

[5] M. Bugajski, T. Piwoński, D. Wawer, T.J. Ochalski, E. Deichsel, P Unger, B. Corbett, Science in Semiconductor Processing, 9, 188, (2006)

[6] T. J. Ochalski, D. Pierścińska, K. Pierściński, M. Bugajski, J. W. Tomm, T. Grunske, A. Kozłowska, Appl. Phys. Lett., 89, 071104, (2006).

[7] P. W. Epperlein,. J. Appl. Phys., 32, (1993)

[8] M. Cardona, Phys. Rev. B, 38, 1806 (1988)

[9] M. Cardona, Modulation Spectroscopy, Academic Press, New York, London, (1969)

[10] E. Matatagui, A. G. Thompson, and Manuel Cardona, Phys. Rev., 176, 950, (1968).

[11] G. Tessier, S. Holé, and D. Fournier, Appl. Phys. Lett., 78, 2267, (1986).

[12] D. Wawer, T.J. Ochalski, T. Piwoński, A. Wójcik - Jedlińska, M. Bugajski, H. Page, Phys. Stat Sol (a), 202, 1227, (2005).

[13] L. R. de Freitas, E. C. da Silva, A. M. Mansanares, G. Tessier and

D. Fournier, J. Appl. Phys., 98, 063508, (2005)

[14] A. Malagg, A. Jasik, M. Teodorczyk, A. Jagoda, A. Kozlowska, IEEE Photon. Tech. Lett, 18, 1582, (2006) 